\title{
Current IGFBP-Related Biomarker Research in Cardiovascular Disease-We Need More Structural and Functional Information in Clinical Studies
}

OPEN ACCESS

Edited by:

Pierre De Meyts,

de Duve Institute, Belgium

Reviewed by:

Cheryl Conover,

Mayo Clinic, United States

Claire Perks,

University of Bristol, United Kingdom

*Correspondence:

Rikke Hjortebjerg

rikke.hjortebjerg@clin.au.dk

Andreas Hoeflich

hoeflich@fbn-dummerstorf.de

Specialty section:

This article was submitted to Molecular and Structural

Endocrinology,

a section of the journal

Frontiers in Endocrinology

Received: 03 May 2018

Accepted: 25 June 2018

Published: 16 July 2018

Citation:

Hoeflich A, David R and Hjortebjerg $R$

(2018) Current IGFBP-Related

Biomarker Research in Cardiovascular

Disease-We Need More Structural

and Functional Information in Clinical

Studies. Front. Endocrinol. 9:388.

doi: 10.3389/fendo.2018.00388

\begin{abstract}
Andreas Hoeflich ${ }^{1 *}$, Robert David ${ }^{2,3}$ and Rikke Hjortebjerg ${ }^{4,5 *}$
'Department of Genome Biology, Leibniz Institute for Farm Animal Biology, Dummerstorf, Germany, ${ }^{2}$ Department of Cardiac Surgery, Reference and Translation Center for Cardiac Stem Cell Therapy, Rostock University Medical Center, Rostock, Germany, ${ }^{3}$ Department Life, Light and Matter, Interdisciplinary Faculty, Rostock University, Rostock, Germany, ${ }^{4}$ Medical Research Laboratory, Department of Clinical Medicine, Faculty of Health, Aarhus University, Aarhus, Denmark, ${ }^{5}$ The Danish Diabetes Academy, Odense, Denmark
\end{abstract}

Cardiovascular diseases are the leading cause of death around the world and the insulin-like growth factor (IGF)-system has multiple functions for the pathological conditions of atherosclerosis. IGF binding proteins (IGFBPs) are widely investigated as biomarkers for pathological disorders, including those of the heart. At the tissue level, IGFBP-1 to -6 decrease bioactivity of IGF-I and -II due to their high affinity IGF-binding sites. By contrast, in the circulation, the IGFBPs increase biological half-life of the IGFs and may therefore be regarded as positive regulators of IGF-effects. The IGFBPs may also exert IGF-independent functions inside or outside the cell. Importantly, the circulating IGFBP-concentrations are regulated by trophic, metabolic, and reproductive hormones. In a multitude of studies of healthy subjects and patients with coronary heart diseases, various significant associations between circulating IGFBP-levels and defined parameters have been reported. However, the complex hormonal and conditional control of IGFBPs may explain the lack of clear associations between IGFBPs and parameters of cardiac failure in broader studies including larger populations. Furthermore, the IGFBPs are subject to posttranslational modifications and proteolytic degradation by proteases, upon which the IGFs are released. In this review, we emphasize that, with the exception of IGFBP-4 and in sharp contrast to the preclinical studies, virtually all clinical studies do not have structural or functional information on their biomarker. The use of analytical systems with no discriminatory potential toward intact vs. fragmented IGFBPs represents a major issue in IGFBP-related biomarker research and an important focus point for the future. Overall, measurements of selected IGFBPs or more complex IGFBP-signatures of the family of IGFBPs have potential to identify pathophysiological alterations in the heart or patients with high cardiovascular risk, particularly if defined cohorts are to be assessed. However, a more thorough understanding of the dynamic IGF-IGFBP system as well as its proteases and protease inhibitors in both normal physiology and in cardiovascular diseases is necessary.

Keywords: IGFBP, PAPP-A, IGFBP-fragment, mortality, cardiovascular diseases, IGF 


\section{INTRODUCTION}

In Europe (1) and in the US (2), cardiovascular diseases are heading the statistics on causes of death. It is well-known that the insulin-like growth factor (IGF)-system actively contributes to the pathological conditions of atherosclerosis, including activation of smooth muscle cells and macrophages, angiogenesis, and restenosis (3). First of all, IGF-I and IGFII are potent stimulators of smooth muscle cell proliferation $(4,5)$. In human arterial smooth muscle cells, IGF-I has been identified as a potent effector of chemotaxis (4). IGF-I has also been shown to increase the release of proinflammatory cytokines and low-density lipoprotein (LDL) uptake, which facilitate atherosclerosis and plaque instability (3). In addition, it is thought that the IGF-system supports accumulation of extracellular matrix in the vessel walls (3), which may occur by the control of matrix degrading enzymes (6). Under conditions of reduced IGF-I concentrations, levels of matrix proteins (actin and procollagen 3A1) are decreased, whereas matrix metalloproteinase levels (MMP-3 and-13) are elevated in smooth muscle cells (6). Supplementation by IGF-I normalizes both matrix proteins and matrix degrading enzymes (6). Interestingly, IGF-I concentrations in in vitro cultivated smooth muscle cells are affected when cell culture medium conditioned by macrophages is used.

IGF bioavailability is strictly regulated by six high-affinity IGF binding proteins (IGFBPs) that are ubiquitously produced in most tissues. The IGFBPs bind the IGFs on a 1:1 molar basis and prevent receptor activation, but they also serve to prolong IGF half-life. IGFBP-3 is the most abundant IGFBP in adult serum with a concentration of approximately $3,000 \mathrm{ng} / \mathrm{mL}$, whereas the remaining IGFBPs circulate at concentrations of $20-500 \mathrm{ng} / \mathrm{mL}$ (7). Due to their affinities and high concentrations, $<1 \%$ of IGF is circulating in the free form $(7,8)$. The acid labile subunit (ALS) is found almost exclusively in the circulation and binds to preformed complexes composed of IGF and IGFBP-3 or IGFBP5. Due to the size of the ternary complex, approximately $80 \%$ of all IGF-I is sequestered in the intravascular compartment. By contrast, the IGFs are predominantly bound to the IGFBPs in binary complexes within tissues (9). Consequently, the IGFBPs create a reservoir of readily available IGF (primarily IGFBP-3 and -5 ) and control tissue-specific efflux and distribution (primarily IGFBP-1,-2, and -4) (1,2). Thus, the IGFBPs serve as important determinants of IGF actions and like the IGFs, the IGFBPs have been suggested to play a role in the pathogenesis of atherosclerosis. Of note, in the fetal and adult human heart, IGFBP-3 appears to be expressed at high levels (10), and in

\footnotetext{
Abbreviations: ACS, acute coronary syndrome; ALS, acid labile subunit; AMI, acute myocardial infarction; CAD, coronary artery disease; CASC, cardiac atrial appendage stem cell; CHD, coronary heart disease; CT, carboxyl-terminal; $\mathrm{CV}$, cardiovascular; CVD, cardiovascular disease; ECG, electrocardiogram; GH, growth hormone; HDL, high-density lipoprotein; IGF, insulin-like growth factor; IGFBP, IGF binding protein; IHD, ischemic heart disease; IMT, intima-media thickness; LDL, high-density lipoprotein; MACE, major adverse cardiac events; MI, myocardial infarction; MMP, matrix metalloproteinase; NSTEMI, no elevation of the ST segment; NT, amino-terminal; PAPP-A, pregnancy-associated plasma protein-A; STEMI, elevation of the ST segment; T2D, type 2 diabetes; TNF, tumor necrosis factor.
}

the developing rat heart, mRNA for IGFBP-3,-4, and -5 has been demonstrated (11). Importantly, based on the GeneCards ${ }^{\mathrm{R}}$ database entries, all IGFBPs can be detected in the normal human heart. Accordingly, several IGFBPs have been suggested as attractive cardiovascular markers, although local vs. systemic effects of IGFBPs in the heart have not been resolved and causal relationships between IGFBP perturbations and the development of atherosclerosis remain to be firmly established (12). While the biomarker potential of growth hormone (GH) or IGF-I in heart failure has been discussed just recently (13), the present review for the first time addresses the biomarker potential of all IGF binding proteins (IGFBPs) in cardiovascular diseases. In order to understand the potential effects of local IGFBPexpression in the heart, the discussion of clinical studies is extended by concepts and hypotheses derived from selected functional studies of IGFBPs in the heart and entire circulatory system. Cardiovascular disease is a group of diseases that includes both the heart and blood vessels, and of which most are caused by atherosclerosis, where the inside of an artery narrows due to the accumulation of an atherosclerotic plaque. Ischemic heart disease [IHD, alternatively coronary artery disease (CAD) or coronary heart disease (CHD)] is the umbrella term for stable and unstable angina, acute myocardial infarction (AMI, commonly known as heart attack), and sudden cardiac death. AMI and unstable angina defines the acute coronary syndrome (ACS). Stroke is the subtype caused by a disruption in the flow of blood to part of the brain either due to blood vessel occlusion (ischemic stroke) or rupture (hemorrhagic stroke). Congestive heart failure is the end stage of several circulatory diseases and characterized by abnormal myocardial function and insufficient ability to maintain blood flow.

On a final note, it should be acknowledged that research in the area is still in its early phases, and larger and more comprehensive investigations are needed to fully assess the biomarker potential of the IGFBPs as well as potential redundancy function within the IGFBP family. Moreover, it is pivotal to appreciate the relation of cause and effect. Most theories derive from findings in crosssectional studies and such observations should be considered as hypothesis generating as they cannot give evidence of causality. Finally, in all paragraphs to come, it is urged to remember that numerous studies have been performed using assays with undocumented specificity toward the IGFBPs, and our evaluation and interpretation of studies should be seen in the light of that.

\section{IGFBP-1}

Much attention has focused on IGFBP-1 as a partaker in metabolic diseases, as it is negatively regulated by insulin, glucose, and GH (14). In prediabetic patients, IGFBP-1 is reduced, but as the disease progresses, so does pancreatic secretory capacity, resulting in chronic insulin deficiency as well as increased IGFBP-1 levels. Thus, the biomarker potential of circulating IGFBP-1 is largely biased by conditional and agerelated insulin or GH-insensitivities. In the heart, IGFBP-1 
expression is differentially regulated by insulin (15). In smooth muscle cells, IGFBP-1 expression (Table 1), which is increased by interleukins and TNFalpha, exerts IGF-dependent as well asindependent effects on cell proliferation (16). Because higher concentrations of IGFBP-1 were found in aortic plaques, IGFBP1 was discussed in the context of plaque stability (16). However, mice overexpressing IGFBP-1 present with reduced blood pressure and increased vascular nitric oxide production, and the overexpression prevents vascular endothelial dysfunction in the mice on high calorie diet [107]. In patients with AMI, significant reductions in serum IGFBP-1 $(\sim 40 \mathrm{ng} / \mathrm{ml})$ when compared to healthy subjects $(\sim 70 \mathrm{ng} / \mathrm{ml})$ have been demonstrated $(20)$. Likewise, in patients with type 2 diabetes (T2D), decreased circulating concentrations of IGFBP-1 were correlated with cardiovascular risk factors such as low high-density lipoprotein (HDL) cholesterol or high blood pressure (17). These correlations have been confirmed by several consecutive studies $(18,19)$. However, in patients with heart failure, IGFBP-1 levels have been shown to be increased, although not associated with outcome (21), and in 112 patients with unstable angina, IGFBP-1 levels correlated with ACS disease severity and are higher in patients with multivessel disease than those with single-vessel (22). High circulating IGFBP-1 was also significantly associated with morbidity and cardiovascular mortality in a study including more than 500 diabetic patients with AMI (23). Thus, it was concluded that metabolic control and hepatic insulin resistance are related to fatal events in diabetic CVD patients. Notably, in the lowest or highest IGFBP-1 tertile, IGFBP-1 concentrations ranged between 2 and 24 or 43 and $677 \mu \mathrm{g} / \mathrm{l}$, respectively (23). In diabetic patients, IGFBP-1 concentrations were associated with those of copeptin, which independently predicted myocardial events, and this could in part explain the prognostic value of IGFBP-1 for heart failure or AMI (56). However, the same association was not found in a more recent study by the same authors (24). On the tissue level, sonography of carotid arteries in type 2 diabetic patients revealed a highly significant negative correlation between IGFBP-1 serum concentrations and thickness of the combined intimal and media compartments (25). Irrespective of diabetes, high IGFBP-1 serum concentrations were correlated with and thus predictive for an increased risk of cardiovascular and coronary heart disease mortality in elderly men (26). Likewise, in survivors of a previous (first) AMI, higher circulating IGFBP-1 concentrations predicted heart failure as demonstrated by a prospective study (27) which included male and female subjects between 45 and 70 years of age. Interestingly, higher IGFBP-1 concentrations were informative for mortality in subjects with no history of heart failure after a follow-up of 8 years. Serum IGFBP-1 concentrations were also significantly increased in patients with critical CAD when compared to patients with less severe CAD (22). In combination with HDL cholesterol, IGFBP-1 serum concentrations were more sensitive and specific for the prediction of CAD (22). Lower IGFBP-1 and IGF-I serum concentrations were associated with an increased risk of IHD later in life or with higher cardiovascular disease mortality in men and women at an age between 51 and 98 years (28). Nevertheless, the authors also concluded that assessment of IGFBP-1 and IGF-I could be used for the identification of adult subjects at an increased risk of fatal
IHD as well as for the selection of an appropriate intervention strategy. The reasons underlying the contradictory biomarker information of IGFBP-1 are not directly evident, because the follow-up periods were 9-13 years in one study (28) and 8 years in the later study (27). A possible explanation may be deduced from the fact that the study by Janszky et al. was restricted to the risk of heart failure but not to all-cause mortality or mortality related to cardiovascular disease. In 335 elderly male subjects (70-89 years of age), IGFBP-1 was not associated with increased prevalence of cardiovascular mortality risk (29). Concentrations of IGFBP1 in the circulation furthermore were not correlated with the prevalence of coronary complications in aged subjects (30). Collectively, these findings suggest that IGFBP-1 may predict future cardiovascular mortality and morbidity, but perhaps more importantly, it may serve as a marker of hyperinsulinemia, which precedes subsequent development of insulin resistance and CVD.

\section{IGFBP-2}

IGFBP-2 has been established as a marker of the metabolic syndrome and therefore, it has been suggested that low concentrations of IGFBP-2 could be a useful biomarker for the assessment of cardiovascular risk factors (31). It is the second most abundant binding protein in circulation and is also metabolically regulated, albeit not as rapidly as IGFBP-1. Indeed, IGFBP-2 levels are reduced in obese subjects and in T2D, and low levels associate with elevated fasting glucose, serum triglycerides, and LDL cholesterol (31). As a particular advantage of IGFBP2 as compared to IGFBP-1, circulating IGFBP-2 concentrations are less prone to post-prandial alterations. This suggests IGFBP2 to represent a more robust biomarker than IGFBP-1 (31). In a cross-sectional study that included 310 study members at an age between 63 and 82 years, circulating IGFBP- 2 concentrations were negatively correlated with arterial intima-media thickness (IMT), whereas IGF-II levels were positively associated with IMT (35). Conversely, IGFBP-2 concentrations in plasma were about 2 -fold increased in 273 cases of fatal IHD and a strong association between IGFBP-2 and death/AMI was described (32). In 99 patients with T2D and 99 controls, IGFBP-2 was inversely associated with pulse wave velocity, which is a measure of arterial stiffness and thus, the degree of atherosclerosis (33). However, these cross-sectional studies reflect associations and give no evidence of causality. In a study by Hedbacker et al. (57), the authors demonstrated a direct beneficial effect of IGFBP2 on cardiovascular risk factors in excessively obese (ob/ob) and diabetic mice. IGFBP-2 overexpression resulted in a 3 -fold increase in hepatic insulin sensitivity and a reduction in plasma glucose, liver triglycerides, and hepatic steatosis. As a result, the diabetic phenotype was remedied. The same reduction in plasma glucose was observed upon overexpression of IGFBP-2 in wild-type mice, and there was a trend for reduction in insulin levels in both models. Considering this association between low IGFBP-2 and multiple CVD risk factors, IGFBP-2 may serve as a robust biomarker for the identification of individuals with high cardiovascular risk. However, IGFBP-2 is also a biomarker of mortality in elderly subjects (34), possibly explained by an 
TABLE 1 | Biomarker potential of IGFBPs in ischemic heart disease.

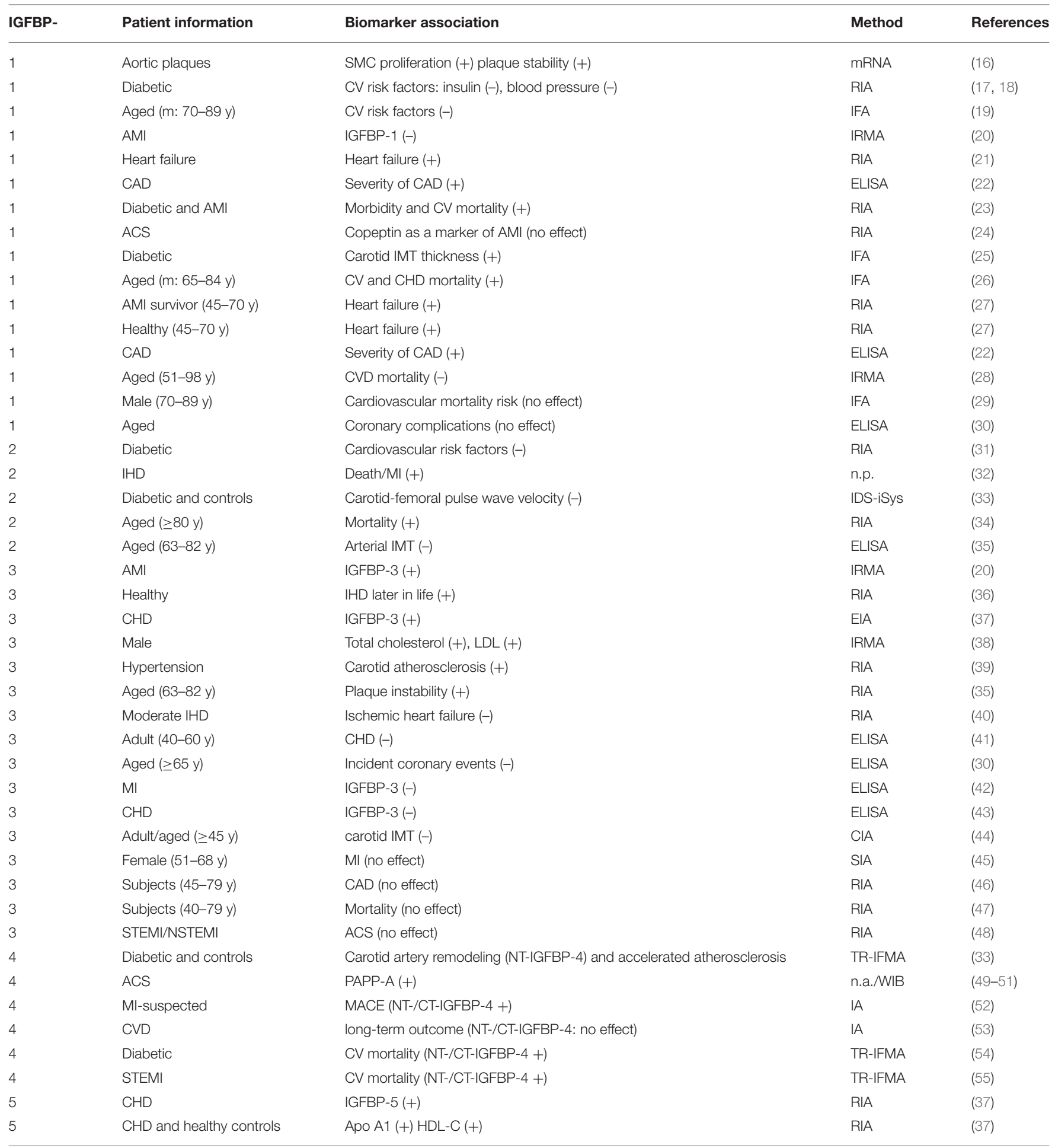

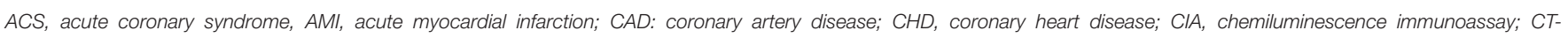

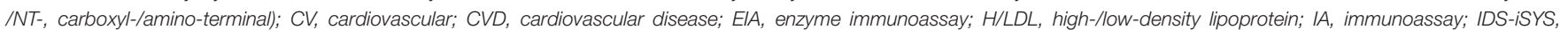

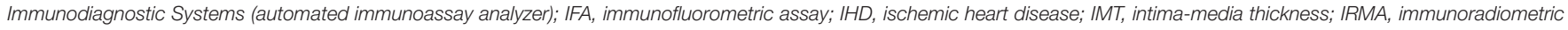

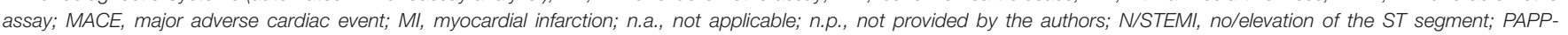

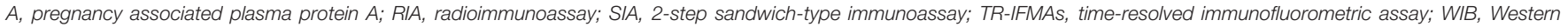
immunoblot. 
association between high serum IGFBP-2 and low physical function. Thus, it might be important to also assess the functional relevance of increased circulating IGFBP-2 levels for CVD in the future.

\section{IGFBP-3}

Due to its abundance in the circulation and role as the primary IGF carrier, substantial attention has been paid to IGFBP-3. Surprisingly, little is known about its regulation with regards to cardiovascular disease. In the human heart, IGFBP-3 is expressed throughout lifetime both on mRNA and protein levels and IGFBP-3 mRNA expression in the heart is higher when compared to the liver at fetal as well as adult stages (10). Interestingly, higher IGFBP-3 protein expression was identified by Western immunoblotting in the ischemic as compared to the hypertrophic or dilated heart (10). Intact IGFBP-3 is secreted by cardiac atrial appendage stem cells (CASCs) and thought to be related to the regenerative potential due to cardiac angiogenesis and possibly also to some extent cardiomyogenic differentiation in the ischemic heart as demonstrated also by Western immunoblotting (58). After heart transplantation, expression of IGBP-3 and IGF-I mRNA was quantified in end-stage dilated $(n=11)$ or ischemic hearts $(n=12)$ (59). Compared to healthy control hearts $(n=10)$, expression of IGFBP-3 mRNA was significantly increased in both pathological conditions, whereas IGF-I mRNA was elevated only in the dilated heart (59). Expression of IGFBP-3 was further discussed in the context of hypoxia and a pathophysiological function of the IGF-system was proposed for the heart. In fact, in cultivated H9c2 myocardial cells, hypoxia increased expression of IGFBP-3, which was responsible for the induction of apoptosis due to inhibition of IGF-signaling via protein kinase B (60). However, on the local level, IGFBP-3 exerted antiproliferative effects on the Wnt signaling pathway in cardiac progenitor cells (61). Thereby, the authors demonstrated that the antiproliferative effect of IGFBP-3 depends on an intact IGF-binding site.

\section{Increased Concentrations of IGFBP-3}

In contrast to IGFBP-1, IGFBP-3, and IGF-I levels significantly increased after AMI (20). The authors were able to specify a threshold of $137 \mathrm{ng} / \mathrm{ml}$ for the serum concentrations of IGF-I: lower concentrations were correlated with a worse prognosis in AMI patients, whereas higher concentrations of IGF-I after AMI were associated with improved functional parameters detected by echo cardiography (e.g., left ventricular mass or ejection fraction) (20). It was suggested that high IGF-I immediately after AMI fueled myocardial remodeling, and that IGFBP-3, which generally reflects total IGF-I levels, increased in parallel. In a prospective study, high IGFBP-3 and low IGF-I serum concentrations in healthy subjects were correlated with an increased risk of developing IHD later in life (36). In partial agreement, higher levels of IGFBP-3 but also higher serum concentrations of IGF-I were described in patients with CHD (37). Under conditions of AMI, an elevation of the ST segment (STEMI) on the electrocardiogram (ECG) is considered to characterize a more severe form of the ACS when compared to patients with no elevation of the ST segment (NSTEMI). In a longitudinal study of 747 White and 544 Black young males over a period of 10 years, an increase of IGFBP-3 serum concentrations over time was associated with significant increases of total cholesterol and LDL cholesterol (38). This study did not confirm previous cross-sectional studies describing associations of IGFBP-3 and IGF-I with hypertension, but rather revealed a link between IGFBP-3 and lipid concentrations in young males. In hypertensive patients, a role of IGFBP-3 in the formation of carotid atherosclerosis was suggested (39). In elderly patients (63-82 years of age), higher circulating concentrations of IGFBP-3 or IGF-I were positively or negatively associated with plaque instability, respectively (35). The authors concluded that IGF-I and IGFBP-3 might represent functional biomarkers for prediction of the risk for plaque rupture or therapeutic targets for stabilization of atherosclerotic plaques. In fact, systemic concentrations of IGFBP-3 and IGF-I were increased after application of the angiotensin-converting enzyme-inhibitor Fosinopril, and the beneficial effects of treatment in IHD were discussed in the context of the IGF-system (62).

\section{Conditions of Decreased Circulating IGFBP-3}

In addition to IGF-I and IGFBP-3, secretion of GH was also impaired in patients with ischemic heart failure (40). The authors observed patient-individual GH-sensitivity related to the degree of left ventricular dysfunction (40). In male patients between 40 and 60 years of age (41) and in adults of both genders older than 65 years (30), lower concentrations of IGFBP-3 or IGF-I in serum were associated with CHD. In patients with AMI, serum levels of IGFBP-3, IGF-I, and IGF-II were decreased immediately after AMI, but returned to their normal range 1 week after coronary intervention (42). Similarly, in 90 patients with a diagnosed CHD, reduced levels of circulating IGFBP-3 and IGF-I were described (43). The results are in principal agreement with a previous report on reduced IGF-I concentrations in patients with AMI (63). In both studies, serum concentrations of GH were increased under conditions of acute cardiac ischemia. Low concentrations of IGFBP-3 and high circulating levels of IGF-I were further associated with an increased thickness of the intima-media (44).

\section{Lack of Biomarker Value for IGFBP-3 Concentrations}

A prospective study in women at 51-68 years of age revealed no direct relationship between IGFBP-3 or IGF-I and a risk of AMI later in life (45). Systemic effects of IGFBP-3 or IGFI on the development of CAD were excluded by a prospective study observing more than 1,000 cases and more than 2000 controls over a mean period of 6 years (46). From this study and from an additional meta-analysis assessing 31 single nucleotide polymorphisms present in the IGF1 and IGFBP3 genes, the authors concluded that neither circulating IGFBP-3 or IGF-I nor the corresponding genes were causative for the development of CAD in human populations. At a later time point, a single nucleotide polymorphism upstream of the IGF1 genomic region was identified in patients at an increased risk of developing CAD 
(64). With respect to IHD, an association between mortality and circulating concentrations of IGFBP-3, IGF-I, or IGF-II was also excluded by a large prospective Japanese study including more than 39,000 subjects between 40 and 79 years of age (47). In a Turkish study including 20 STEMI patients, 10 NSTEMI patients, and 20 healthy controls, IGFBP- 3 was not affected by ACS (48). Instead, IGF-I was severely reduced in ACS patients with elevations of the ST segment on the ECG (48). Therefore, IGF-I serum concentrations were suggested to represent potential biomarkers of myocardial necrosis in the STEMI group of ACS patients.

\section{Age-Related Biomarker Potential of IGFBP-3}

Interestingly, age-related discrepancies exist in the IGFand IGFBP-concentrations after AMI as analyzed by RIA (65). Accordingly, younger subjects ( $<50$ years of age) are characterized by higher absolute concentrations and lower daily variations of circulating IGF-I when compared to more aged subjects ( $>50$ years of age), which may be related to higher regenerative capacities in younger subjects after AMI (65). Age-related differences of IGF-I and IGFBP-3 in the context of differential prognosis after AMI also might indicate an involvement of GH during functional recovery of the infarcted heart. The inclusion of structural information (intact vs. fragmented IGFBPs) could be used in order to assess age-related control of IGF-bioactivity.

\section{IGFBP-4 AND PAPP-A}

IGFBP-4, also an abundant IGFBP, has been suggested in numerous studies to be directly involved in the inhibition of atherosclerosis $(33,52,54,55,66,67)$. As demonstrated on the level of mRNA and protein, intact IGFBP-4 is produced by a variety of cell types and represents the major IGFBP secreted by myoblasts (68-70). It is considered to attenuate IGF activity in most physiological contexts and inhibits proliferation and differentiation during the transition from myoblasts to myotubes (68). Studies suggest that intact IGFBP-4 modulates cardiac development and cardiomyocyte differentiation (70) and is actively involved in the development of atherosclerosis, with high expression levels in aorta lesional areas (66). Moreover, mice with an overproduction of IGFBP-4 present with smooth muscle hypoplasia (71). IGFBP-4 has a preferential affinity for IGFII over IGF-I and transports them to peripheral tissues, where proteases cleave IGFBP-4 into low binding-affinity fragments (72-74). The enzyme pregnancy-associated plasma protein-A (PAPP-A) has been identified as the principal, if not only, protease responsible for this IGF-dependent cleavage of IGFBP$4(75,76)$, and PAPP-A levels strongly correlate with the levels of IGFBP-4 proteolytic fragments (54). PAPP-A tethers to cell surfaces, and thus, release of the IGFs occurs in close proximity to the IGF-IR and increases IGF bioavailability primarily at local sites (77). Interestingly, balloon injury of porcine coronary arteries has been shown to massively increase the expression of PAPP-A and the subsequent degradation of IGFBP-4 in the neointimal and medial layers, peaking at 4 weeks after treatment, thus causing possible hyperplasia and coronary restenosis (71). In a study of patients with T2D and healthy controls, IGFBP4 fragment levels were associated with the normalized wallindex, which is a measure of carotid artery remodeling and accelerated atherosclerosis (33). In murine models, deletion of the PAPP-A gene resulted in an $80 \%$ reduction in atherosclerotic area, whereas transgenic overexpression of PAPP-A accelerated plaque progression $(66,78)$. Inhibition of the PAPP-A substrate binding site with a neutralizing monoclonal PAPP-A antibody caused a $70 \%$ reduction in plaque area (79). Importantly, when PAPP-A is deprived of its proteolytic activity, intact IGFBP-4 levels increase and diminish the actions of IGF-I. Collectively, the findings suggest that high PAPP-A and low IGFBP-4 levels may exacerbate the pathophysiological processes underlying plaque development. Under conditions of myocardial damage, PAPP-A concentrations are also increased in the circulation (49). In 2001, Bayes-Genis et al. were the first to demonstrated that PAPP-A was ubiquitously expressed in human eroded atherosclerotic plaques, and serum levels were elevated in patients with ACS (50). This initiated a large interest to study PAPP-A as a candidate marker of plaque burden and CVD. However, it was later revealed that administration of heparin to AMI patients, which is part of the standard initial treatment, results in a rapid increase in PAPP-A concentrations, possibly through a displacement of cell surface attached PAPP-A (51). Instead, Postnikov et al. proposed that quantification of the PAPP-A generated, cleaved amino-terminal (NT) and carboxyl-terminal (CT) fragments of IGFBP-4 could be reflective of PAPP-A enzymatic activity and hereby serve as prognostic biomarkers $(12,52)$. In patients with symptoms of IHD, both fragments were increased in the case of short-term cardiac events (coronary bypass, AMI, or cardiac death) (52). However, in a follow-up study by the same authors, neither IGFBP-4 fragments nor PAPP-A sufficed to predict the long-term outcome in patients with stable cardiovascular disease (53). The varying results may relate to differences in follow-up period and number of patients and hence, events. Recently, the fragments were shown to prognosticate cardiovascular mortality in 330 type 1 diabetes patients without cardiovascular disease at baseline during 12 years of follow-up (54) and in 656 patients with STEMI followed for 5 years (55). Importantly, it was also verified that the IGFBP-4 fragments, unlike PAPP-A, were unaffected by heparin treatment of coronary patients (80). Interestingly, accumulating evidence argues for multiple IGF-independent functions of IGFBP-4. In IGF-insensitive colorectal cancer cells, recombinant human IGFBP-4 was able to efficiently block colony formation (81), and in P19CL6 or in embryonic stem cells, knockdown of IGFBP-4 was shown to alter cardiomyogenesis and cardiac regeneration (70). The mechanism was mediated through inhibition of canonical Wnt signaling and not through IGF. In mice, an IGFBP-4 variant blocked translocation of beta-catenin to the cell nucleus in the ischemic heart (82). Injection of IGFBP-4/H95P directly after AMI prevented betacatenin related DNA-damage in cardiomyocytes and reduced infarct size 4 weeks after AMI in the mouse (82). Because IGFBP-4/H95P is lacking the intact IGF-binding domain, the 
protective effect of mutated IGFBP-4 in the ischemic heart is IGF-independent.

\section{IGFBP-5}

IGFBP-5 is produced and secreted by numerous cell types, including vascular smooth muscle cells, and its expression is increased within atherosclerotic plaques (83). Furthermore, atherosclerotic arteries exhibit staining of IGFBP- 5 staining along intimal plaques (84). In a cross-sectional study of 95 male CHD patients and 92 healthy controls, elevations of IGFBP-5 and acid labile subunit (ALS) were measured in serum (37). In addition, IGF-I, IGF-II, IGFBP-3, and ALS were increased under conditions of CHD in the patients (37). In serum, concentrations of IGFBP-5 were significantly correlated with the levels of IGF-I and -II or IGFBP-3 (37). The increased concentrations of IGFBPs including IGFBP-5 and ALS could be causative for the larger amounts of IGF-I and -II in CHD patients (37).

Under ischemic conditions, local expression of IGFBP5 mRNA, which succeeds the initiation of IGF-II mRNA expression, is thought to terminate cardioprotection exhibited by IGF-II (85-87). In fact, a dual role has been suggested for IGFBP-5, with positive effects on IGF-I-stimulated differentiation of myoblasts in vitro, yet inhibitory effects on IGF-II activity (68). Thus, the association of IGFBP-5 with atherosclerosis may indicate a direct stimulatory effect of IGFBP-5 on smooth muscle cell proliferation and plaque formation.

\section{IGFBP-6}

IGFBP-6 exerts both IGF-dependent and -independent effects in various cell types (88). In endomycardial biopsies from 12 patients, IGFBP-6 mRNA expression was increased after explantation of a left ventricular assist device when compared to biopsies sampled during implantation (89). Because other proteins in the IGF-system, including IGF-I, IGF-II, and IGFBP4 , were also increased after reverse remodeling of the heart, it was concluded that local effects of the IGF-system are active during heart recovery (89)-yet, a direct link to IHD remains unestablished. However, increased expression of IGFBP-6 after prolonged hypoxia has been observed in vascular endothelial cells (90). Notably, the IGFBP6 gene promotor contains several hypoxia response elements, which could explain the increased expression of IGFBP-6 (90). IGFBP-6 levels were also increased after hypoxia in vascular endothelial cells (90). However, since expression of IGFBP-1 was increased as an earlier response to hypoxemic conditions $(91,92)$ than IGFBP-6, this may be interpreted as an example of molecular job sharing between distinct members of the IGFBP-family.

\section{SUMMARY AND CONCLUSIONS}

So far, clinical studies have demonstrated positive or negative associations and a number of studies have also concluded that the IGFBPs show no prognostic value in the assessment of cardiovascular risk. Certainly, one reason for the controversies present in the literature could be the fact that the IGF system is involved in so many biological processes, and hence, the complex nature and multifunctional properties of the IGFBPs. Firstly, alterations in IGFBP levels may represent a phenomenon caused by the disease per se. However, most patients receive medical therapy, which affects several components of the IGF-system and constitutes a significant confounder. The effect of heparin on the IGFBP-4 protease PAPP-A is an example of that. Acute patients often also present with an altered peripheral tissue perfusion, allowing leakage of tissue-localized IGFBPs. Furthermore, IGFBP levels may also fluctuate due to compensatory mechanisms or be affected by age or metabolism. It is well-established that IGFBPs are controlled by both $\mathrm{GH}$ and insulin, and under conditions of acute or prolonged illness, altered secretory patterns of GH and insulin can increase or decrease levels of IGFBPs (65, 93). Secondly, assessment of IGFBP biomarker potential highly depends on accurate measurements of the IGFBP. Thus, it is important to know of the factors that can potentially skew these measurements and it is crucial that immunoassays are based on antibodies that recognize all clinically relevant forms of the analyte. Unfortunately, most studies use immunoassays without information on target epitopes, and it is well-known that many assays exhibit cross-reactivity toward structurally similar IGFBPs or are unable to discriminate between various IGFBP forms (80). Since the IGFBPs can be proteolytically degraded by proteases, resulting in circulating IGFBP fragments, it is crucial that the assays can distinguished between intact and fragmented IGFBP. Several proteases have been identified, and although these proteases, like most other members of the IGF system, appear under the strict control of paracrine and endocrine influences, our knowledge on factors that control protease activity and tissue distribution is far from sufficient (12). Additionally, the IGFBPs are subject to post-translational modifications such as phosphorylation and glycosylation and may also be partially truncated or in complex with other proteins. Indeed, it is known that the glycosylation patterns of many proteins are altered in various disease states $(94,95)$, and it is likely that both proteolysis and post-translational modifications of the IGFBPs are influenced by an acute setting and differs from that of stable patients (96). Thus, the use of analytical systems with no discriminatory potential toward intact or modified IGFBPs represents a major issue in IGFBP-related biomarker research, and we prospectively need to include structural and functional information on the IGFBPs. This issue, which is not restricted to CVC patients, further raises concerns regarding the reliability and consequently, the utility of IGFBPs, and at present, identification of patients with high CVD risk cannot solely rely on IGFBP measurements.

It should be noted that research in the area is still in its early phases, and we advocate that larger and more comprehensive investigations are implemented before evaluating the biomarker potential of the IGFBPs. Investigations so far have mostly been limited to cross-sectional studies and animal studies, and cautious interpretation is necessary, as data should be confirmed by longitudinal and mechanistic studies. Accordingly, broader population studies including more complex settings of pathophysiological conditions in their subjects may come to the 
conclusion that no associations are present between circulating IGFBPs and cardiovascular parameters. We speculate that the inclusion of patients with a higher degree of overlap with respect to their pathophysiology could improve the assessment of the biomarker potential of the IGFBPs.

Our understanding of the IGFBPs has advanced throughout recent years, and the clear link between the IGFBPs and a number of pathological conditions has preserved the interest in identifying novel biomarkers that may help improve future diagnosis and prognosis. However, studies regarding CVD have been varying and discrepant, and it remains unknown to what extent IGFBP measurements possess clinical value, in particular in the absence of structural and functional information on the IGFBPs. Further understanding of the IGF system in both

\section{REFERENCES}

1. Key Figures on Europe. Luxenbourg: Publications Office of the European Union (2017).

2. Xu JD, Murphy SL, Kochanek KD, Arias E. Mortality in the United States, 2015. Hyattsville, MD: National Center for Health Statistics (2016).

3. Bayes-Genis A, Conover CA, Schwartz RS, The insulin-like growth factor axis: a review of atherosclerosis and restenosis. Circ Res. (2000) 86:125-30. doi: 10.1161/01.RES.86.2.125

4. Bornfeldt KE, Raines EW, Nakano T, Graves LM, Krebs EG, Ross R. Insulinlike growth factor-I and platelet-derived growth factor-BB induce directed migration of human arterial smooth muscle cells via signaling pathways that are distinct from those of proliferation. J Clin Invest. (1994) 93:1266-74. doi: 10.1172/JCI117081

5. Zaina S, Pettersson L, Thomsen AB, Chai CM, Qi Z, Thyberg J, et al. Shortened life span, bradycardia, and hypotension in mice with targeted expression of an Igf2 transgene in smooth muscle cells. Endocrinology (2003) 144:2695-703. doi: 10.1210/en.2002-220944

6. von der Thusen JH, Borensztajn KS, Moimas S, van Heiningen S, Teeling $\mathrm{P}$, van Berkel TJ, et al. IGF-1 has plaque-stabilizing effects in atherosclerosis by altering vascular smooth muscle cell phenotype. Am J Pathol. (2011) 178:924-34. doi: 10.1016/j.ajpath.2010.10.007

7. Rajaram S, Baylink DJ, Mohan S. Insulin-like growth factor-binding proteins in serum and other biological fluids: regulation and functions. Endocrine Rev. (1997) 18:801-31. doi: 10.1210/er.18.6.801

8. Frystyk J, Skjærbæk C, Dinesen B, Ørskov H. Free insulin-like growth factors (IGF-I and IGF-II) in human serum. FEBS Lett. (1994) 348:185-91. doi: 10.1016/0014-5793(94)00602-4

9. Binoux M, Hossenlopp P. Insulin-Like Growth Factor (IGF) and IGF-Binding Proteins: Comparison of Human Serum and Lymph. J Clin Endocrinol Metab. (1988) 67:509-14. doi: 10.1210/jcem-67-3-509

10. Granata R, Broglio F, Migliorino D, Cutrupi S, Baldanzi G, Sireno M, et al. Neonatal and adult human heart tissues from normal subjects and patients with ischemic, dilated or hypertrophic cardiomyopathy express insulinlike growth factor binding protein-3 (IGFBP-3). J Endocrinol Invest. (2000) 23:724-6. doi: 10.1007/BF03345060

11. Cerro JA, Grewal A, Wood TL, Pintar JE. Tissue-specific expression of the insulin-like growth factor binding protein (IGFBP) mRNAs in mouse and rat development. Regul Pept. (1993) 48:189-98. doi: 10.1016/0167-0115(93)90347-B

12. Hjortebjerg R. IGFBP-4 and PAPP-A in normal physiology and disease. Growth Horm Igf Res. (2018) 41:7-22. doi: 10.1016/j.ghir.2018.05.002

13. Marra AM, Bobbio E, D’Assante R, Salzano A, Arcopinto M, Bossone E, et al. Growth hormone as biomarker in heart failure. Heart Fail Clin. (2018) 14:65-74. doi: 10.1016/j.hfc.2017.08.008

14. Hoeflich A, Russo VC. Physiology and pathophysiology of IGFBP-1 and IGFBP-2 - consensus and dissent on metabolic control and malignant normal physiology and specifically in CVD is necessary to avoid misinterpretations.

\section{AUTHOR CONTRIBUTIONS}

$\mathrm{AH}$ wrote the manuscript and prepared the table; $\mathrm{RD}$ revised the manuscript; $\mathrm{RH}$ wrote the manuscript.

\section{FUNDING}

RH was funded by the Danish Diabetes Academy supported by the Novo Nordisk Foundation. RD is supported by the FORUN Program of Rostock University Medical Centre, the DAMP Foundation and the BMBF (VIP+00240). potential. Best practice \& research. Clin Endocrinol Metabol. (2015) 29:685700. doi: 10.1016/j.beem.2015.07.002

15. Bar RS, Boes M, Clemmons DR, Busby WH, Sandra A, Dake BL, et al. Insulin differentially alters transcapillary movement of intravascular IGFBP1, IGFBP-2 and endothelial cell IGF-binding proteins in the rat heart. Endocrinology (1990) 127:497-9. doi: 10.1210/endo-127-1-497

16. Wang J, Razuvaev A, Folkersen L, Hedin E, Roy J, Brismar K, et al. The expression of IGFs and IGF binding proteins in human carotid atherosclerosis, and the possible role of IGF binding protein-1 in the regulation of smooth muscle cell proliferation. Atherosclerosis (2012) 220:1029. doi: 10.1016/j.atherosclerosis.2011.10.032

17. Gibson JM, Westwood M, Young RJ, White A. Reduced insulin-like growth factor binding protein-1 (IGFBP-1) levels correlate with increased cardiovascular risk in non-insulin dependent diabetes mellitus (NIDDM). $J$ Clin Endocrinol Metab. (1996) 81:860-3.

18. Janssen JA, Stolk RP, Pols HA, Grobbee DE, Lamberts SW. Serum total IGF-I, free IGF-I, and IGFB-1 levels in an elderly population: relation to cardiovascular risk factors and disease. Arterioscler Thromb Vasc Biol. (1998) 18:277-82. doi: 10.1161/01.ATV.18.2.277

19. Harrela M, Koistinen R, Tuomilehto J, Nissinen A, Seppala M. Low serum insulin-like growth factor-binding protein-1 is associated with an unfavourable cardiovascular risk profile in elderly men. Ann Med. (2000) 32:424-8. doi: 10.3109/07853890008995950

20. Lee WL, Chen JW, Ting CT, Lin SJ, Wang PH. Changes of the insulinlike growth factor I system during acute myocardial infarction: implications on left ventricular remodeling. J Clin Endocrinol Metab. (1999) 84:1575-81. doi: 10.1210/jc.84.5.1575

21. Faxen UL, Hage C, Benson L, Zabarovskaja S, Andreasson A, Donal E, et al. HFpEF and HFrEF display different phenotypes as assessed by IGF-1 and IGFBP-1. J Cardiac Failure (2017) 23:293-303. doi: $10.1016 / j$.cardfail.2016.06.008

22. Zheng $\mathrm{W}$, Lai $\mathrm{Y}$, Jin $\mathrm{P}, \mathrm{Gu} \mathrm{W}$, Zhou Q, Wu X. Association of circulating IGFBP1 level with the severity of coronary artery lesions in patients with unstable angina. Disease Mark. (2017) 2017:1917291. doi: $10.1155 / 2017 / 1917291$

23. Wallander M, Norhammar A, Malmberg K, Ohrvik J, Ryden L, Brismar K. IGF binding protein 1 predicts cardiovascular morbidity and mortality in patients with acute myocardial infarction and type 2 diabetes. Diabetes Care (2007) 30:2343-8. doi: $10.2337 / \mathrm{dc} 07-0825$

24. Arnetz L, Hage C, Brismar K, Catrina SB, Norhammar A, Lundman P, et al. Copeptin, insulin-like growth factor binding protein-1 and sitagliptin: a report from the BEta-cell function in Glucose abnormalities and Acute Myocardial Infarction study. Diabetes Vasc Dis Res. (2016) 13:307-11. doi: $10.1177 / 1479164116635997$

25. Leinonen ES, Salonen JT, Salonen RM, Koistinen RA, Leinonen PJ, Sarna SS, et al. Reduced IGFBP-1 is associated with thickening of the carotid wall in type 2 diabetes. Diabetes Care (2002) 25:1807-12. doi: 10.2337/diacare.25.10.1807 
26. Harrela M, Qiao Q, Koistinen R, Tuomilehto J, Nissinen A, Seppala M, et al. High serum insulin-like growth factor binding protein-1 is associated with increased cardiovascular mortality in elderly men. Horm Metab Res. (2002) 34:144-9. doi: 10.1055/s-2002-23198

27. Janszky I, Hallqvist J, Ljung R, Hammar N. Insulin-like growth factor binding protein-1 is a long-term predictor of heart failure in survivors of a first acute myocardial infarction and population controls. Int J Cardiol. (2010) 138:50-5. doi: 10.1016/j.ijcard.2008.08.003

28. Laughlin GA, Barrett-Connor E, Criqui MH, Kritz-Silverstein D. The prospective association of serum insulin-like growth factor I (IGF-I) and IGFbinding protein-1 levels with all cause and cardiovascular disease mortality in older adults: the Rancho Bernardo Study. J Clin Endocrinol Metab. (2004) 89:114-20. doi: 10.1210/jc.2003-030967

29. Kalme T, Seppala M, Qiao Q, Koistinen R, Nissinen A, Harrela M, et al. Sex hormone-binding globulin and insulin-like growth factor-binding protein-1 as indicators of metabolic syndrome, cardiovascular risk, and mortality in elderly men. J Clin Endocrinol Metab. (2005) 90:1550-6. doi: 10.1210/jc.2004-0762

30. Kaplan RC, McGinn AP, Pollak MN, Kuller LH, Strickler HD, Rohan TE, et al. Association of total insulin-like growth factor-I, insulin-like growth factor binding protein-1 (IGFBP-1), and IGFBP-3 levels with incident coronary events and ischemic stroke. J Clin Endocrinol Metab. (2007) 92:1319-25. doi: 10.1210/jc.2006-1631

31. Heald AH, Kaushal K, Siddals KW, Rudenski AS, Anderson SG, Gibson JM. Insulin-like growth factor binding protein-2 (IGFBP-2) is a marker for the metabolic syndrome. Exp Clin Endocrinol Diabetes (2006) 114:371-6. doi: 10.1055/s-2006-924320

32. Halim SA, Neely ML, Pieper KS, Shah SH, Kraus WE, Hauser ER, et al. Simultaneous consideration of multiple candidate protein biomarkers for long-term risk for cardiovascular events. Circulation (2015) 8:168-77. doi: 10.1161/CIRCGENETICS.113.000490

33. Hjortebjerg R, Laugesen E, Høyem P, Oxvig C, Stausbøl-Grøn B, Knudsen ST, et al. The IGF system in patients with type 2 diabetes: associations with markers of cardiovascular target organ damage. Eur J Endocrinol. (2017) 176:521-31. doi: 10.1530/EJE-16-0940

34. van den Beld AW, Blum WF, Brugts MP, Janssen JA, Grobbee DE, Lamberts SW. High IGFBP2 levels are not only associated with a better metabolic risk profile but also with increased mortality in elderly men. Eur J Endocrinol. (2012) 167:111-7. doi: 10.1530/EJE-12-0160

35. Martin RM, Gunnell D, Whitley E, Nicolaides A, Griffin M, Georgiou N, et al. Associations of insulin-like growth factor (IGF)-I, IGF-II, IGF binding protein (IGFBP)-2 and IGFBP-3 with ultrasound measures of atherosclerosis and plaque stability in an older adult population. J Clin Endocrinol Metab. (2008) 93:1331-8. doi: 10.1210/jc.2007-2295

36. Juul A, Scheike T, Davidsen M, Gyllenborg J, Jorgensen T. Low serum insulin-like growth factor I is associated with increased risk of ischemic heart disease: a population-based case-control study. Circulation (2002) 106:93944. doi: 10.1161/01.CIR.0000027563.44593.CC

37. Fischer F, Schulte H, Mohan S, Tataru MC, Kohler E, Assmann G, et al. Associations of insulin-like growth factors, insulin-like growth factor binding proteins and acid-labile subunit with coronary heart disease. Clin Endocrinol. (2004) 61:595-602. doi: 10.1111/j.1365-2265.2004.02136.x

38. Colangelo LA, Liu K, Gapstur SM. Insulin-like growth factor-1, insulin-like growth factor binding protein-3, and cardiovascular disease risk factors in young black men and white men: the CARDIA Male Hormone Study. Am J Epidemiol (2004) 160:750-7. doi: 10.1093/aje/kwh289

39. Watanabe $T$, Itokawa $M$, Nakagawa $Y$, Iguchi $T$, Katagiri $T$. Increased levels of insulin-like growth factor binding protein-3 in hypertensive patients with carotid atherosclerosis. Am J Hyperten. (2003) 16:754-60. doi: 10.1016/S0895-7061(03)00985-3

40. Osterziel KJ, Blum WF, Strohm O, Dietz R. The severity of chronic heart failure due to coronary artery disease predicts the endocrine effects of short-term growth hormone administration. J Clin Endocrinol Metab. (2000) 85:1533-9. doi: 10.1210/jcem.85.4.6575

41. Akanji AO, Suresh CG, Al-Radwan R, Fatania HR. Insulin-like growth factor (IGF)-I, IGF-II and IGF-binding protein (IGFBP)-3 levels in Arab subjects with coronary heart disease. Scand J Clin Lab Invest. (2007) 67:553-9. doi: 10.1080/00365510601173153
42. Hu WS, Hwang JM. Association of serum cytokines, human growth hormone, insulin-like growth factor (IGF)-I, IGF-II and igf-binding protein (IGFBP)-3 with Coronary artery disease. Chin J Physiol. (2012) 55:267-73. doi: 10.4077/CJP.2012.BAA043

43. Kucukhuseyin O, Toptas B, Timirci-Kahraman O, Isbir S, Karsidag K, Isbir T. The effect of GHR/exon-3 polymorphism and serum GH, IGF-1 and IGFBP-3 Levels in Diabetes and Coronary Heart Disease. In vivo (2015) 29:371-8.

44. Spilcke-Liss E, Friedrich N, Dorr M, Schminke U, Volzke H, Brabant G, et al. Serum insulin-like growth factor I and its binding protein 3 in their relation to intima-media thickness: results of the study of health in Pomerania (SHIP). Clin Endocrinol. (2011) 75:70-5. doi: 10.1111/j.1365-2265.2011.04010.x

45. Page JH, Ma J, Pollak M, Manson JE, Hankinson SE. Plasma insulinlike growth factor 1 and binding-protein 3 and risk of myocardial infarction in women: a prospective study. Clin Chem. (2008) 54:1682-8. doi: 10.1373/clinchem.2008.105825

46. Ricketts SL, Rensing KL, Holly JM, Chen L, Young EH, Luben R, et al. Prospective study of insulin-like growth factor-I, insulin-like growth factorbinding protein 3, genetic variants in the IGF1 and IGFBP3 genes and risk of coronary artery disease. Int J Mol Epidemiol Genet. (2011) 2:261-85.

47. Iso H, Maruyama K, Ikehara S, Yamagishi K, Tamakoshi A. Cellular growth factors in relation to mortality from cardiovascular disease in middle-aged Japanese: the JACC study. Atherosclerosis (2012) 224:154-60. doi: 10.1016/j.atherosclerosis.2012.05.026

48. Sekuri C, Arslan O, Utuk O, Bayturan O, Onur E, Tezcan UK, et al. [Serum level of insulin-like growth factor-1 and insulin-like growth factor binding protein-3 in acute coronary syndromes and relationship with prognosis]. Anadolu kardiyol derg. (2004) 4:209-12.

49. Khosravi J, Diamandi A, Krishna RG, Bodani U, Mistry J, Khaja N. Pregnancy associated plasma protein-A: ultrasensitive immunoassay and determination in coronary heart disease. Clin Biochem. (2002) 35:531-8.

50. Bayes-Genis A, Conover CA, Overgaard MT, Bailey KR, Christiansen $\mathrm{M}$, Holmes DR, et al. Pregnancy-associated plasma protein a as a marker of acute coronary syndromes. N Engl J Med. (2001) 345:1022-9. doi: 10.1056/NEJMoa003147

51. Terkelsen CJ, Oxvig C, Nørgaard BL, Glerup S, Poulsen TS, Lassen JF, et al. Temporal course of pregnancy-associated plasma protein-A in angioplastytreated ST-elevation myocardial infarction patients and potential significance of concomitant heparin administration. Am J Cardiol. (2009) 103:29-35. doi: 10.1016/j.amjcard.2008.08.027

52. Postnikov AB, Smolyanova TI, Kharitonov AV, Serebryanaya DV, Kozlovsky SV, Tryshina YA, et al. N-terminal and C-terminal fragments of IGFBP-4 as novel biomarkers for short-term risk assessment of major adverse cardiac events in patients presenting with ischemia. Clin Biochem. (2012) 45:519-24. doi: 10.1016/j.clinbiochem.2011.12.030

53. Schulz O, Postnikov AB, Smolyanova TI, Katrukha AG, Schimke I, Jaffe AS. Clinical differences between total PAPP-A and measurements specific for the products of free PAPP-A activity in patients with stable cardiovascular disease. Clin Biochem. (2014) 47:177-83. doi: 10.1016/j.clinbiochem.2013.10.027

54. Hjortebjerg R, Tarnow L, Jorsal AH. Parving H, Rossing P, Bjerre M, et al. IGFBP-4 fragments as markers of cardiovascular mortality in type 1 diabetes patients with and without nephropathy. J Clin Endocrinol Metabol. (2015) 100:3032-40. doi: 10.1210/jc.2015-2196

55. Hjortebjerg R, Lindberg S, Pedersen S, Mogelvang R, Jensen JS, Oxvig $\mathrm{C}$, et al. Insulin-like growth factor binding protein 4 fragments provide incremental prognostic information on cardiovascular events in patients with st-segment elevation myocardial infarction. J Am Heart Assoc. (2017) 6: e005358. doi: 10.1161/JAHA.116.005358

56. Mellbin LG, Ryden L, Brismar K, Morgenthaler NG, Ohrvik J, Catrina SB. Copeptin, IGFBP-1, and cardiovascular prognosis in patients with type 2 diabetes and acute myocardial infarction: a report from the DIGAMI 2 trial. Diabetes Care (2010) 33:1604-6. doi: 10.2337/dc10-0088

57. Hedbacker K, Birsoy K, Wysocki RW, Asilmaz E, Ahima RS, Farooqi IS, et al. Antidiabetic effects of IGFBP2, a leptin-regulated gene. Cell Metab. (2010) 11:11-22. doi: 10.1016/j.cmet.2009.11.007

58. Fanton Y, Houbrechts C, Willems L, Daniels A, Linsen L, Ratajczak J, et al. Cardiac atrial appendage stem cells promote angiogenesis in vitro and in vivo. J Mol Cell Cardiol. (2016) 97:235-44. doi: 10.1016/j.yjmcc.2016. 06.005 
59. Pucci A, Zanini C, Granata R, Ghignone R, Iavarone A, Broglio F, et al. Myocardial insulin-like growth factor-1 and insulin-like growth factor binding protein-3 gene expression in failing hearts harvested from patients undergoing cardiac transplantation. J Heart Lung Transplant. (2009) 28:4025. doi: 10.1016/j.healun.2008.12.022

60. Chang RL, Lin JW, Hsieh DJ, Yeh YL, Shen CY, Day CH, et al. Long-term hypoxia exposure enhanced IGFBP-3 protein synthesis and secretion resulting in cell apoptosis in H9c2 myocardial cells. Growth factors (Chur, Switzerland) (2015) 33:275-81. doi: 10.3109/08977194.2015.1077824

61. Oikonomopoulos A, Sereti KI, Conyers F, Bauer M, Liao A, Guan J, et al.Wnt signaling exerts an antiproliferative effect on adult cardiac progenitor cells through IGFBP3. Circulation Res. (2011) 109:1363-74. doi: 10.1161/CIRCRESAHA.111.250282

62. Giovannini S, Cesari M, Marzetti E, Leeuwenburgh C, Maggio M, Pahor M. Effects of ACE-inhibition on IGF-1 and IGFBP-3 concentrations in older adults with high cardiovascular risk profile. J Nutr Health Aging (2010) 14:457-60. doi: 10.1007/s12603-010-0036-7

63. Friberg L, Werner S, Eggertsen G, Ahnve S. Growth hormone and insulinlike growth factor-1 in acute myocardial infarction. Eur Heart $J$ (2000) 21:1547-54. doi: 10.1053/euhj.2000.2125

64. Lin HL, Ueng KC, Wang HL, Chen TP, Yang SF, Chu SC,et al. The impact of IGF-I gene polymorphisms on coronary artery disease susceptibility. J Clin Lab Anal. (2013) 27:162-9. doi: 10.1002/jcla.21581

65. Reeves I, Abribat T, Laramee P, Jasmin G, Brazeau P. Age-related serum levels of insulin-like growth factor-I, -II and IGF-binding protein-3 following myocardial infarction. Growth Horm IGF Res. (2000) 10:78-84. doi: 10.1054/ghir.2000.0143

66. Conover CA, Mason MA, Bale LK, Harrington SC, Nyegaard M, Oxvig C, et al. Transgenic overexpression of pregnancy-associated plasma proteinA in murine arterial smooth muscle accelerates atherosclerotic lesion development. Am J Physiol Heart Circ Physiol. (2010) 299:H284-91. doi: 10.1152/ajpheart.00904.2009

67. Konev AA, Smolyanova TI, Kharitonov AV, Serebryanaya DV, Kozlovsky SV, Kara AN et al. Characterization of endogenously circulating IGFBP4 fragments-Novel biomarkers for cardiac risk assessment. Clin Biochem. (2015) 48:774-80. doi: 10.1016/j.clinbiochem.2015.05.010

68. Ewton DZ, Coolican SA, Mohan S, Chernausek SD, Florini JR. Modulation of insulin-like growth factor actions in L6A1 myoblasts by insulin-like growth factor binding protein (IGFBP)-4 and IGFBP-5: a dual role for IGFBP-5. J Cell Physiol. (1998) 177:47-57.

69. Xue Y, Yan Y, Gong H, Fang B, Zhou Y, Ding Z, et al. Insulin-like growth factor binding protein 4 enhances cardiomyocytes induction in murine-induced pluripotent stem cells. J Cell Biochem. (2014) 115:1495-504. doi: $10.1002 /$ jcb. 24804

70. Zhu W, Shiojima I, Ito Y, Li Z, Ikeda H, Yoshida M, et al. IGFBP-4 is an inhibitor of canonical Wnt signalling required for cardiogenesis. Nature (2008) 454:345-9. doi: 10.1038/nature07027

71. Bayes-Genis A, Schwartz RS, Lewis DA, Overgaard MT, Christiansen $\mathrm{M}$, Oxvig $\mathrm{C}$, et al. Insulin-like growth factor binding protein-4 protease produced by smooth muscle cells increases in the coronary artery after angioplasty. Arterioscler Thromb Vasc Biol. (2001) 21:335-41. doi: 10.1161/01.ATV.21.3.335

72. Hjortebjerg R, Flyvbjerg A, Frystyk J. Insulin growth factor binding proteins as therapeutic targets in type 2 diabetes. Expert Opin Ther Targets (2014) 18:209-24. doi: 10.1517/14728222.2014.858698

73. Hjortebjerg R, Berryman D, Comisford R, List E, Oxvig C, Bjerre $\mathrm{M}$, et al. Depot-specific and GH-dependent regulation of IGF binding protein-4, pregnancy-associated plasma protein-A, and stanniocalcin-2 in murine adipose tissue. Growth Horm IGF Res. (2018) 39:54-61. doi: 10.1016/j.ghir.2018.01.001

74. Gude MF, Hjortebjerg R, Oxvig C, Thyø AA, Magnusson NE, Bjerre M, et al. PAPP-A, IGFBP-4 and IGF-II are secreted from human adipose tissue cultures in a depot-specific manner. Eur J Endocrinol. (2016) 175:509-19. doi: 10.1530/EJE-16-0569

75. Lawrence JB, Oxvig C, Overgaard MT, Sottrup-Jensen L, Gleich GJ, Hays LG, et al. The insulin-like growth factor (IGF)-dependent IGF binding protein4 protease secreted by human fibroblasts is pregnancy-associated plasma protein-A. PNAS (1999) 96:3149-53.
76. Bayes-Genis A, Schwartz RS, Lewis DA, Overgaard MT, Christiansen M, Oxvig C, et al. Insulin-Like Growth Factor Binding Protein-4 Protease Produced by Smooth Muscle Cells Increases in the Coronary Artery After Angioplasty. Arterioscler Thromb Vasc Biol. (2001) 21:335-41. doi: 10.1161/01.ATV.21.3.335

77. Laursen LS, Kjaer-Sorensen K, Andersen MH, Oxvig C. Regulation of Insulin-Like Growth Factor (IGF) bioactivity by sequential proteolytic cleavage of IGF binding protein-4 and-5. Mol Endocrinol.(2007) 21:1246-57. doi: 10.1210/me.2006-0522

78. Harrington SC, Simari RD, Conover CA. Genetic deletion of pregnancy-associated plasma protein-A is associated with resistance to atherosclerotic lesion development in apolipoprotein E-deficient mice challenged with a high-fat diet. Circ Res. (2007) 100:1696-702. doi: 10.1161/CIRCRESAHA.106.146183

79. Conover CA, Bale LK, Oxvig C. targeted inhibition of pregnancy-associated plasma protein-a activity reduces atherosclerotic plaque burden in mice. $J$ Cardiovasc Transl Res. (2016) 9:77-9. doi: 10.1007/s12265-015-9666-9

80. Hjortebjerg R, Lindberg S, Hoffmann S, Jensen JS, Oxvig C, Bjerre M, et al. PAPP-A and IGFBP-4 fragment levels in patients with ST-elevation myocardial infarction treated with heparin and PCI. Clin Biochem. (2015) 48:322-8. doi: 10.1016/j.clinbiochem.2014.11.022

81. Diehl D, Hoeflich A, Wolf E, Lahm H. Insulin-like growth factor (IGF)-binding protein-4 inhibits colony formation of colorectal cancer cells by IGF-independent mechanisms. Cancer Res. (2004) 64:1600-3. doi: 10.1158/0008-5472.CAN-03-2844

82. Wo D, Peng J, Ren DN, Qiu L, Chen J, Zhu Y, et al. Opposing roles of Wnt inhibitors IGFBP-4 and Dkk1 in cardiac ischemia by differential targeting of LRP5/6 and $\beta$-catenin. Circulation (2016) 134:1991-2007. doi: 10.1161/CIRCULATIONAHA.116.024441

83. Zheng B, Duan C, Clemmons DR. The effect of extracellular matrix proteins on porcine smooth muscle cell insulin-like growth factor (IGF) Binding protein-5 synthesis and responsiveness to IGF-I. J Biol Chem. (1998) 273:8994-9000.

84. Kim KS, Seu YB, Baek SH, Kim MJ, Kim KJ, Kim JH, et al. Induction of cellular senescence by insulin-like growth factor binding protein-5 through a p53-dependent mechanism. Mol Biol Cell (2007) 18:4543-52. doi: 10.1091/mbc.e07-03-0280

85. Vogt AM, Htun P, Kluge A, Zimmermann R, Schaper W. Insulin-like growth factor-II delays myocardial infarction in experimental coronary artery occlusion. Cardiovascular Res(1997) 33:469-77.

86. Kluge A, Zimmermann R, Munkel B, Verdouw PD, Schaper J, Schaper W. Insulin-like growth factor II is an experimental stress inducible gene in a porcine model of brief coronary occlusions. Cardiovascular Res. (1995) 29:708-16.

87. Deindl E, Schaper W. Gene expression after short periods of coronary occlusion. Mol Cell Biochem. (1998) 186:43-51.

88. Bach LA. Current ideas on the biology of IGFBP-6: More than an IGF-II inhibitor? Growth Horm IGF Res. (2016) 30-1:81-6. doi: 10.1016/j.ghir.2016.09.004

89. Barton PJ, Felkin LE, Birks EJ, Cullen ME, Banner NR, Grindle $\mathrm{S}$, et al. Myocardial insulin-like growth factor-I gene expression during recovery from heart failure after combined left ventricular assist device and clenbuterol therapy. Circulation (2005) 112:I46-50. doi: 10.1161/01.CIRCULATIONAHA.105.525873

90. Zhang C, Lu L, Li Y, Wang X, Zhou J, Liu Y, et al. IGF binding protein6 expression in vascular endothelial cells is induced by hypoxia and plays a negative role in tumor angiogenesis. Int J Cancer (2012) 130:2003-12. doi: 10.1002/ijc.26201

91. Kajimura S, Aida K, Duan C. Insulin-like growth factor-binding protein-1 (IGFBP-1) mediates hypoxia-induced embryonic growth and developmental retardation. Proc Natl Acad Sci U S A. (2005) 102:1240-5. doi: 10.1073/pnas.0407443102

92. Tazuke SI, Mazure NM, Sugawara J, Carland G, Faessen GH, Suen LF, et al. Hypoxia stimulates insulin-like growth factor binding protein 1 (IGFBP-1) gene expression in HepG2 cells: a possible model for IGFBP-1 expression in fetal hypoxia. Proc Natl Acad Sci U S A. (1998) 95:10188-93.

93. Mesotten D, Van den Berghe G. Changes within the GH/IGF-I/IGFBP axis in critical illness. Crit Care Clin. (2006) 22:17-28. doi: 10.1016/j.ccc.2005.09.002 
94. Konev AA, Serebryanaya DV, Koshkina EV, Rozov FN, Filatov VL, Kozlovsky SV, et al. Glycosylated and non-glycosylated NT-IGFBP-4 in circulation of acute coronary syndrome patients. Clin Biochem. (2018) 55:56-62. doi: 10.1016/j.clinbiochem.2018.03.004

95. Konev AA, Postnikov AB, Seferian KR, Koshkina EV, Katrukha AG. Nglycosylation of NT-IGFBP-4 does not influence its immunodetection by the neo-epitope specific sandwich immunoassay. 68th American Association for Clinical Chemistry Annual Scientific Meeting. Abstract (2016).

96. Cwyfan Hughes SC, Cotterill AM, Molloy AR., Cassell TB, Braude N, Hinds CJ, et al. The induction of specific proteases for insulin-like growth factor-binding proteins following major heart surgery. J. Endocrinol. (1992) 135:135-45. doi: 10.1677/joe.0.13 50135
Conflict of Interest Statement: AH is related to Ligandis UG.

The remaining authors declare that the research was conducted in the absence of any commercial or financial relationships that could be construed as a potential conflict of interest.

Copyright (c) 2018 Hoeflich, David and Hjortebjerg. This is an open-access article distributed under the terms of the Creative Commons Attribution License (CC BY).

The use, distribution or reproduction in other forums is permitted, provided the original author(s) and the copyright owner(s) are credited and that the original publication in this journal is cited, in accordance with accepted academic practice. No use, distribution or reproduction is permitted which does not comply with these terms. 